\title{
Mapping the affective syndrome in Alzheimer's disease
}

\author{
Topografia da síndrome afetiva na doença de Alzheimer \\ Elisa de Paula França Resende ${ }^{1,2}$, Paulo Caramelli1,2
}

1 Universidade Federal de Minas Gerais, Faculdade de Medicina, Departamento de Clínica Médica, Belo Horizonte MG, Brazil;

Universidade Federal de Minas Gerais, Hospital das Clínicas, Serviço de Neurologia, Belo Horizonte MG, Brazil.

Correspondence:

Paulo Caramelli; Departamento de Clínica Médica, Faculdade de Medicina da UFMG; Av. Prof. Alfredo Balena, 190 / Sala 246; 30130-100 Belo Horizonte MG, Brasil;

E-mail:caramelli@ufmg.br

Conflict of interest:

There is no conflict of interest to declare.

Received 27 May 2015; Accepted 05 June 2015

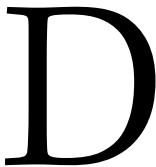

ementia due to Alzheimer's disease $(\mathrm{AD})$ is becoming more frequent with the rapid growing of life expectancy and also with the continuous improvement of the clinical diagnosis ${ }^{1}$. Neuropsychiatric symptoms are very common over the course of AD dementia, adding substantial burden for families and caregivers ${ }^{2}$. These symptoms are usually fluctuating in intensity and are often difficult to be treated. Apathy is the most common behavioral disorder across all stages of $\mathrm{AD}^{2,3}$. Depression and anxiety are also very common, especially in mild and moderate stages, frequently worsening cognitive and functional performances ${ }^{2}$. The main neuropsychiatric symptoms of dementia can be easily assessed by the Neuropsychiatric Inventory (NPI) ${ }^{4}$.

The neural correlates of these behavioral symptoms have been explored in several structural neuroimaging studies, mainly with magnetic resonance imaging (MRI) using voxel-based morphometry (VBM). In one study ${ }^{5}$ conducted with this technique delusions were associated with atrophy in the left frontal lobe, right frontoparietal cortex and left claustrum. Apathy was associated with atrophy in anterior cingulate, medial frontal cortex and putamen bilaterally, and also with the head of left caudate nucleus. Agitation correlated with gray matter loss in left insula and anterior cingulate cortex bilaterally. Another study ${ }^{6}$ showed that agitation was related to atrophy in the left inferior and middle frontal/ insula and bilateral retrosplenial cortices. Aberrant motor behavior was related to atrophy in the right basal ganglia and right inferior frontal cortex, and depression, with atrophy in the left middle frontal cortex.

Voxel-based cortical thickness (VBCT) also seems to be a good way to assess atrophy, allowing identification of structural changes several years before the emergence of dementia $^{7}$. In this issue of Arquivos de Neuro-Psiquiatria, Hayata and colleagues ${ }^{8}$ used the VBCT technique to contrast $\mathrm{AD}$ dementia patients and elderly cognitively healthy controls, and found similar results to those reported with $\mathrm{VBM}^{9}$. The investigators found widespread cortical atrophy in the $\mathrm{AD}$ group, involving the left middle and inferior temporal gyri, posterior regions of right superior temporal sulcus, isthmus of the cingulate gyrus, left posterior cingulate cortex, and right fusiform gyrus. They also found atrophy in the frontal and parietal lobes, insula, entorhinal cortex, precuneus and anterior cingular cortex, all of them bilaterally. The authors found significant correlations between affective syndrome (depression and anxiety) with reduced cortical thickness in the insula, lateral orbitofrontal and temporal pole, all from the right side. Conversely, they found no correlation with other behavioral syndromes, namely, apathy, psychosis and hyperactivity.

These results are very interesting, once the cortical areas which correlated with affective syndromes are involved in the process of emotional experiences (insula) and socioemotional processing (orbitofrontal cortex and right temporal pole). Previous studies $^{5,6}$ also found correlations between depression and anxiety with different cerebral regions, especially frontolimbic areas. The most intriguing result from Hayata et al. study is the lack of correlation with apathy, the neuropsychiatric syndrome which displays the most robust neural correlate, i.e., the medial prefrontal cortex ${ }^{10,11}$. Probably, as the authors included patients with moderate dementia, the overlap of various neuropsychiatric symptoms may have made it difficult to identify a pure correlation. Moreover, the sample size may have influenced the analyses. 
In conclusion, this nice study explores another method to assess gray matter atrophy on MRI in dementia. The correlation between affective syndrome and regions related to socioemotional processing is an interesting finding.
Certainly, new studies with this technique will contribute to better understanding of the neurobiology of neuropsychiatric symptoms in $\mathrm{AD}$, bringing more possibilities for the development of new therapeutic approaches in the future.

\section{References}

1. Prince M, Bryce R, Albanese E, Wimo A, Ribeiro W, Ferri CP.The global prevalence of dementia: a systematic review and metaanalysis. Alzheimers Dement; 2013;9(1):63-75.e2. http://dx.doi.org/10.1016/j.jalz.2012.11.007

2. Aalten P, Verhey FRJ, Boziki M, Bullock R, Byrne EJ, Camus V et al. Neuropsychiatric syndromes in dementia. Results from the European Alzheimer Disease Consortium: part I. Dement Geriatr Cogn Disord; 2007;24:457-63. http://dx.doi.org/10.1159/000110738

3. Tatsch MF, Bottino CM, Azevedo D, Hototian SR, Moscoso MA, Folquitto JC et al. Neuropsychiatric symptoms in Alzheimer disease and cognitively impaired, nondemented elderly from a community-based sample in Brazil: prevalence and relationship with dementia severity. Am J Geriatr Psychiatry; 2006;14(5):438-45. http://dx.doi.org/10.1097/01.JGP.0000218218.47279.db

4. Cummings JL, Mega M, Gray K, Rosenberg-Thompson S, Carusi DA, Gornbein J. The Neuropsychiatric Inventory: comprehensive assessment of psychopathology in dementia. Neurology. 1994;44(12):2308-14. http://dx.doi.org/10.1212/WNL.44.12.2308

5. Bruen PD, McGeown WJ, Shanks MF, Venneri A. Neuroanatomical correlates of neuropsychiatric symptoms in Alzheimer's disease. Brain. 2008;131(9):2455-63. http://dx.doi.org/10.1093/brain/awn151

6. HuX, Meiberth D, Newport B, Jessen F. Anatomical correlates of the neuropsychiatric symptoms in Alzheimer's disease. Curr Alzheimer Res. 2015;12(3):266-77. http://dx.doi.org/10.2174/1567205012666150302154914

7. Fischl B, Dale AM. Measuring the thickness of the human cerebral cortex from magnetic resonance images. Proc Natl Acad Sci U S A. 2000;97(20):11050-5. http://dx.doi.org/ 10.1073/pnas.200033797

8. Hayata TT, Bergo FPG, Rezende TJ, Damasceno A, Damasceno BP, Cendes F et al. Cortical correlates of affective syndrome in dementia due to Alzheimer's disease. Arq Neuropsiquiatr. 2015;73(7): 553-60. http://dx.doi.org/10.1590/0004-282X20150068

9. Frisoni GB, Testa C, Zorzan A, Sabattoli F, Beltramello A, Soininen H, Laakso MP. Detection of grey matter loss in mild Alzheimer's disease with voxel based morphometry. J Neurol Neurosurg Psychiatry. 2002;73(6):657-64. http://dx.doi.org/10.1136/jnnp.73.6.657

10. Guimarães HC, Levy R, Teixeira AL, Beato RG, Caramelli P. Neurobiology of apathy in Alzheimer's disease. Arq Neuropsiquiatr. 2008;66(2B):436-43. http://dx.doi.org/10.1590/S0004-282X2008000300035

11. Lavretsky H, Ballmaier M, Pham D, Toga A, Kumar A. Neuroanatomical characteristics of geriatric apathy and depression: a magnetic resonance imaging study. Am J Geriatr Psychiatry. 2007;15(5):386-94. http://dx.doi.org/10.1097/JGP.0b013e3180325a16 